\title{
Genetic Variability of Reproductive Traits in Common Carpetgrass
}

\author{
Long Ma \\ Everglades Research and Education Center, University of Florida/Institute \\ of Food and Agricultural Sciences, Belle Glade, FL 33430
}

Kevin E. Kenworthy

Department of Agronomy, University of Florida, Gainesville, FL 32611

Huangjun Lu${ }^{1}$ and Ronald Cherry

Everglades Research and Education Center, University of Florida/Institute of Food and Agricultural Sciences, Belle Glade, FL 33430

Additional index words. common carpetgrass, heritability, number of branch, seed set rate, spikelets per branch, variation

\begin{abstract}
Common carpetgrass is a warm-season grass species that is commonly used as a pasture grass in Louisiana and as an alternative low-maintenance lawn grass in the southern Unites States. Understanding genetic variation for traits related to seed production is important to determine breeding strategies for improvement. Ten genotypes were analyzed for number of branches per inflorescence, number of spikelets per branch, and percentage seed set under self-pollination and open pollination. The 10 genotypes exhibited a wide range of variation for number of spikelets per branch and seed set but had a narrow range of variation for number of branches per inflorescence. Genotype was more important than year in contributing to number of branches per inflorescence, whereas the year variance component had a greater impact on number of spikelets per branch. The relative importance of genotype and environment for seed set differed between the two modes of pollination. Broad-sense heritability was 0.35 for number of branches per inflorescence and 0.07 for number of spikelets per branch. Heritability of seed set was 0.29 when the inflorescences were selfed and 0.50 when the inflorescences were subjected to open pollination. Average percentage seed set of the 10 genotypes under self-pollination and open pollination was not significantly different. However, two of 10 genotypes had significantly different means for seed set between selfpollination and open pollination. This information should be useful to plant breeders to select appropriate breeding methods for cultivar development of common carpetgrass.
\end{abstract}

Turfgrasses in the United States are classified as warm-season and cool-season species depending on the adaptation of each species to temperature. Warm-season grasses, originated from tropical regions, are best adapted to temperatures between 27 and $35^{\circ} \mathrm{C}$ and primarily used in the southern United States. Two species, Bermudagrass [Cynodon dactylon var. dactylon (L.) Pers.] and St. Augustinegrass [Stenotaphrum secundatum (Walt.) Kuntze], dominate warm-season turfgrass production (Duble, 2013; Greene et al., 2008a). However, many cultivars of these two species require more intensive management to produce goodquality turf. Other warm-season grass species have been evaluated as alternatives with decreased management inputs (Duncan, 2000; Hanna, 1995; Hughes et al., 2002; Mancino, 1988; Riordan, 1991).

Common carpetgrass (Axonopus fissifolius Raddi) is a warm-season species native to Central America, South America, and the Caribbean (Bush, 1997). This grass was introduced

Received for publication 14 Apr. 2014. Accepted for publication 14 May 2014.

${ }^{1}$ To whom reprint requests should be addressed; e-mail hjlu@ufl.edu. into the United States through New Orleans during the early 1800 s (Piper and Carrier, 1920). As a result of its low-maintenance requirements, common carpetgrass has been widely used as a pasture grass in Louisiana (Watson and Burson, 1985). It has also been naturalized in Texas, Mississippi, Alabama, Florida, Oklahoma, Arkansas, Georgia, South Carolina, and North Carolina (Hitchcock, 1950). Common carpetgrass can be used as an alternative low-maintenance lawn grass because it will persist and produce an acceptable turf surface with minimal amounts of applied nitrogen (Bush, 1997).

Common carpetgrass is a perennial, stoloniferous grass with folded vernation, a continuous collar, no auricle, and a hairy, short ligule fused at the base of the leaf. It has a boat-shaped leaf tip and flattened leaf sheath (Bruneau et al., 2008). The seed head of common carpetgrass usually includes two to three raceme-type branches with the upper two branches approximate and the third remote (Heath et al., 1985). Each spikelet on the raceme is $\approx 2 \mathrm{~mm}$ long and arranged in two alternating rows (Bogdan, 1977). Genetic variations of turf quality and morphological traits including some reproduction-related characteristics have been recently documented (Greene et al., 2008a, 2008b).
Common carpetgrass can be propagated both sexually and vegetatively (Heath et al., 1985). Although the turf can be easily established from sprigs, plugs, or sod, planting seed is a rapid and inexpensive method to establish a lawn because this grass germinates and establishes quickly (Bush, 1997). To produce adequate and high-quality seed of common carpetgrass, it is desirable to understand the inheritance of traits related to seed production.

Pollination type, which is the key factor for determination of appropriate methods to be used to improve a plant species in a breeding program, differs among different warmseason turfgrass species. Bermudagrass has a high degree of self-incompatibility with self-pollinated seed set ranging from $0.10 \%$ to $8.09 \%$ for different types of populations. The seed set for open pollination ranged from $2.8 \%$ to $57 \%$ among the populations (Kenna et al., 1983; Richardson et al., 1978). Seed set varies between diploid and tetraploid bahiagrass (Paspalum notatum Flüggé). Diploid bahiagrass was reported to have a $12 \%$ mean seed set for self-pollination and 39\% for open pollination indicating moderate selfincompatibility. Sexual tetraploid bahiagrass had mean seed set of $21 \%$ and $27 \%$ for selfand open pollination, respectively, whereas artificially induced tetraploid had only $2 \%$ mean seed set for self-pollination and 14\% for open pollination (Acuña et al., 2007). Seashore paspalum (Paspalum vaginatum $\mathrm{Sw}$ ) is highly self-incompatible with a mean seed set of $0.02 \%$ for self-pollination and $7.7 \%$ to $66.3 \%$ for cross-pollination (Wang, 2012). Common carpetgrass can both selfand open-pollinate (Watson and Burson, 1985). However, there is no information comparing seed set between these two modes of pollination.

The objectives of this study were to compare seed set of common carpetgrass under self-pollination and open pollination and to estimate heritabilities of seed set, number of branches per inflorescence, and number of spikelets per branch.

\section{Materials and Methods}

Plant materials. Common carpetgrass germplasm used in this study were maintained in an open/air flow greenhouse of the Agronomy Department at the University of Florida, Gainesville, FL. The germplasm collection was previously characterized for morphological traits and turfgrass performance characteristics by Greene et al. (2008a, 2008b) . Each plant in this collection represents a different accession. Ten accessions were randomly selected and vegetatively propagated to produce four plants per accession. Each propagated plant was grown in a $10-\mathrm{cm}$ diameter pot filled with metro-mix 900 potting soil with fertilizers added. The 40 plants were arranged in a randomized complete block design with four replications and 10 genotypes per replication in a greenhouse. All plants were trimmed to a uniform height after establishment. The study was replicated 
over two time periods from Sept. 2012 to Dec. 2012 (Year 1) and from Feb. 2013 to May 2013 (Year 2). The plants were watered daily to field capacity and fertilized every 2 weeks with $30 \mathrm{~mL}$ liquid fertilizers containing $0.24 \%$ nitrogen, $0.04 \%$ phosphorus, and $0.13 \%$ potassium. Supplemental lighting was provided to extend daylength to $14 \mathrm{~h}$.

Pollination and percentage seed set calculation. Three inflorescences from each pot were enclosed with a glassine bag that was supported by a wooden dowel before anthesis for self-pollination. The bottom of each bag was folded and stabilized with a paper clip. Open pollination was accomplished by wind dispersion of pollen among the 40 plants. Greenhouse sidewall curtains remained open/up on both sides most of the time during anthesis to enhance wind dispersion and cross-pollination. One month after anthesis, the three self-pollinated and an additional three open-pollinated inflorescences from each pot were cut, dried at 50 to $55^{\circ} \mathrm{C}$ for $2 \mathrm{~d}$, and then bleached with $50 \%$ bleach solution for $2 \mathrm{~h}$ to clear the floral bracts for easy observation of seed set. Number of branches, number of spikelets per branch, and number of seed were counted for each inflorescence. Percentage seed set per genotype was calculated using the formula: percentage seed set $=(\#$ seed $/$ \#spikelets per inflorescence) $\times 100$.

Statistical analysis. Data were analyzed as a split plot with year being main plots and genotypes being subplots. Expected mean squares for each source of variation are listed in Table 1. The SAS PROC GLM procedure (SAS, 2012) was used for calculating the mean squares of each source of variation for number of branches, spikelets per branch, and percentage seed set. Broad-sense heritabilities $\left(\mathrm{H}^{2}\right)$ for the number of branches, spikelets per branch, and percentage seed set were calculated using the formula (Greene et al., 2008a): $H^{2}=\sigma_{G}^{2} /\left(\sigma_{G}^{2}+\frac{\sigma_{G Y}^{2}}{Y}+\frac{\sigma_{E}^{2}}{R Y}\right)$, where $\sigma_{G}^{2}$ is variance of genotypes, $\sigma_{G Y}^{2}$ is variance of genotype-by-year interaction, $\sigma_{E}^{2}$ represents variance of residuals, $\mathrm{Y}$ is the number of years, and $\mathrm{R}$ is the number of replications. Differences in percentage seed set means among 10 genotypes were compared using least significant difference (LSD) test for selfpollination and open pollination separately (SAS, 2012). Contrast tests were performed to determine if differences existed within genotypes for percentage seed set between selfing and open pollination (SAS, 2012).

\section{Results and Discussion}

Number of spikelets per branch and percentage seed set under both pollination conditions exhibited a wide range of distribution, whereas number of branches per inflorescence had a narrow range among the 10 genotypes studied (Table 2). Number of spikelets per branch ranged from nine to 39 . Seed set under self-pollination ranged from $20 \%$ to $88 \%$ and from $18 \%$ to $93 \%$ for open pollination. These ranges and mean seed set
( $50 \%$ and $49 \%$, respectively) indicate that carpetgrass sets seed equally under both modes of pollination. Although observations have been previously made on a number of morphological and turf performance traits including stolon length, nodes, internodes, leaf length and width, density, turf visual quality, etc. (Greene et al., 2008a, 2008b; Skerman and Riveros, 1990; Turgeon, 2005), this is the first reporting of variability for percentage seed set in common carpetgrass.

Estimates of variance (Table 2) showed that genotype was more important than year in contributing to number of branches per inflorescence. Variance of year and genotypeby-year interaction for number of spikelets per branch was much higher than variance resulting from genotype indicating that the environment contributed greatly to the overall phenotype. For seed set, variance of genotype was higher than variance of year when the inflorescences were open-pollinated, whereas variance of genotype was lower than variance of year when the inflorescences were selfpollinated. In both pollination types, the genotype $\times$ year variance was higher than variance of genotype indicating that the environment had a significant influence on seed set. Broad-sense heritability was low (0.07) for number of spikelets per branch. The similar low heritability was previously observed in other crops such as maize (Hallauer, 1970) and peanut (Anderson et al., 1991). Number of branches had an estimated heritability of 0.35 . Seed set under self-pollination and cross-pollination had heritabilities of 0.29 and 0.50 , respectively.

In the contrast analysis (Table 3), two of the 10 genotypes had significantly different means for seed set between self-pollination and open pollination. Genotype UFA32 had a higher seed set under selfing than when open-pollinated, whereas UFA10 exhibited greater seed set when open-pollinated. Overall, data in Table 3 indicated that pollination type did not influence seed set and that carpetgrass is capable of being self- and cross-pollinated. In addition, LSD tests showed that seed set for self- and open pollination varied greatly among the 10 genotypes. Genotype UFA38 had superior self-compatibility and UFA 15 had the best cross-compatibility.

With a few exceptions, turfgrasses can be generally established by planting seed. Seeding is less expensive and requires less labor than sodding, but seed of some grass species such as bahiagrass germinates slowly (Trenholm et al., 2011) and takes longer to form a uniform turf

Table 1. Expected mean squares from analysis of variance for data on 10 genotypes of common carpetgrass.

\begin{tabular}{llcl}
\hline Sources of variation & \multicolumn{1}{c}{$\mathrm{df}$} & Mean squares & Expected mean squares \\
\hline Year (Y) & $\mathrm{y}-1$ & $\mathrm{M}_{1}$ & $\sigma_{\mathrm{e}}^{2}+\mathrm{g} \sigma_{\mathrm{r}(\mathrm{y})}^{2}+\mathrm{rg} \sigma_{\mathrm{y}}^{2}$ \\
Replication (R)/Y & $\mathrm{y}(\mathrm{r}-1)$ & $\mathrm{M}_{2}$ & $\sigma_{\mathrm{e}}^{2}+\mathrm{g} \sigma_{\mathrm{r}(\mathrm{y})}^{2}$ \\
Genotype (G) & $\mathrm{g}-1$ & $\mathrm{M}_{3}$ & $\sigma_{\mathrm{e}}^{2}+\mathrm{r} \sigma^{2}{ }_{\mathrm{gy}}+\mathrm{ry} \sigma_{\mathrm{g}}^{2}$ \\
$\mathrm{G} \times \mathrm{Y}$ & $(\mathrm{g}-1)(\mathrm{y}-1)$ & $\mathrm{M}_{4}$ & $\sigma_{\mathrm{e}}^{2}+\mathrm{r} \sigma^{2}{ }_{\mathrm{gy}}$ \\
Error $(\mathrm{E})$ & $\mathrm{y}(\mathrm{r}-1)(\mathrm{g}-1)$ & $\mathrm{M}_{5}$ & $\sigma_{\mathrm{e}}^{2}$ \\
\hline
\end{tabular}

Table 2. Estimate of variance components, broad-sense heritabilities, minimum, maximum and mean values for number of branches, spikelets per branch, and seed set under self- and open pollination in common carpetgrass.

\begin{tabular}{lcccc}
\hline & & & \multicolumn{2}{c}{ Seed set (\%) } \\
\cline { 3 - 5 } Source & No. of branches & Spikelets/branch & Self-pollination & Open pollination \\
\hline Year (Y) & 0.01 & 10.16 & 44.4 & 21.5 \\
Replication (R)/Y & 0 & 0 & 0 & 20.7 \\
Genotype (G) & 0.02 & 0.30 & 21.6 & 47.9 \\
$\mathrm{G} \times \mathrm{Y}$ & 0.02 & 5.25 & 71.0 & 62.5 \\
$\mathrm{H}^{2}$ & 0.35 & 0.07 & 0.29 & 0.50 \\
Minimum & 2 & 9 & 20 & 18 \\
Maximum & 4 & 39 & 88 & 93 \\
Mean & 3 & 23 & 50 & 49 \\
\hline
\end{tabular}

Table 3. Percentage seed set of 10 genotypes of common carpetgrass under different pollination modes and comparison of means within each genotype and between genotypes.

\begin{tabular}{|c|c|c|c|c|c|c|}
\hline \multirow[b]{2}{*}{ Genotype } & \multicolumn{2}{|c|}{ Self-pollination } & \multicolumn{2}{|c|}{ Open pollination } & \multirow[b]{2}{*}{$\mathrm{F}^{\mathrm{z}}$} & \multirow[b]{2}{*}{$P^{z}$} \\
\hline & Mean \pm SE & $\overline{\text { Range }}$ & Mean \pm SE & $\overline{\text { Range }}$ & & \\
\hline UFA2 & $57 \pm 14 \mathrm{AB}^{\mathrm{y}}$ & $36-83$ & $58 \pm 11 \mathrm{~A}$ & $43-70$ & 0.01 & 0.9203 \\
\hline UFA10 & $35 \pm 15 \mathrm{C}$ & $20-65$ & $47 \pm 14 \mathrm{ABC}$ & $35-77$ & 5.14 & 0.0468 \\
\hline UFA15 & $58 \pm 11 \mathrm{AB}$ & $41-73$ & $63 \pm 14 \mathrm{~A}$ & $53-93$ & 1 & 0.3403 \\
\hline UFA21 & $49 \pm 14 \mathrm{ABC}$ & $33-69$ & $48 \pm 16 \mathrm{ABC}$ & $28-79$ & 0.45 & 0.5191 \\
\hline UFA29 & $38 \pm 7 \mathrm{BC}$ & $30-49$ & $33 \pm 10 \mathrm{C}$ & $18-49$ & 1.39 & 0.2654 \\
\hline UFA32 & $52 \pm 11 \mathrm{ABC}$ & $33-68$ & $35 \pm 10 \mathrm{BC}$ & $22-52$ & 39.97 & $<0.0001$ \\
\hline UFA38 & $61 \pm 26 \mathrm{~A}$ & $25-88$ & $52 \pm 16 \mathrm{ABC}$ & $25-76$ & 1.79 & 0.2111 \\
\hline UFA60 & $46 \pm 9 \mathrm{ABC}$ & $31-60$ & $45 \pm 15 \mathrm{ABC}$ & $18-66$ & 0.01 & 0.9061 \\
\hline UFA72 & $52 \pm 12 \mathrm{ABC}$ & $26-65$ & $56 \pm 17 \mathrm{AB}$ & $24-74$ & 0.42 & 0.533 \\
\hline UFA99 & $51 \pm 14 \mathrm{ABC}$ & $37-61$ & $56 \pm 16 \mathrm{AB}$ & $34-87$ & 0.52 & 0.4888 \\
\hline
\end{tabular}

${ }^{\mathrm{z}} \mathrm{F}$ test and the $P$ value are for comparison of means under different pollination types within each genotype. ${ }^{\mathrm{y}}$ Means within each column followed by the same letter are not significantly different $(\alpha=0.05)$ between genotypes determined with a least significant difference test. 
cover, which allows biotic stress such as weeds and abiotic stress such as soil erosion to occur. Common carpetgrass germinates and establishes rapidly. Hence, seeding common carpetgrass is a commonly used method to establish a lawn (Bush, 2000). Improvement of seed production in common carpetgrass can be achieved by increasing branches/ inflorescence, spikelets/branch, seed set, or a combination of the traits. Our study showed a narrow range for branches/inflorescence and a low heritability for spikelets/branch. Therefore, it will be difficult to improve these two traits. Seed set had a wide range of distribution and the heritability of seed set was 0.29 in the selfed flowers and 0.50 in the open-pollinated flowers. It appears that a plant breeder can develop cultivars with high percent seed set and good turf quality.

The breeding approach for cultivar development is dependent on the pollination type that a plant species has (Acquaah, 2007). Common carpetgrass can be self-pollinated to produce seeds and thus cultivars derived from purelines can be developed through single plant selection and selfing. On the other hand, when averaged over the 10 genotypes, the seed set of self-pollinated and open-pollinated inflorescences did not differ significantly. A considerable amount of selfing can be expected when the female parents without emasculation are openpollinated for breeding purposes. The presence of a great number of inbreds among progeny can significantly decrease the probability of identifying superior hybrid combinations. As a result, development of hybrid cultivars or synthetic varieties in common carpetgrass, which requires cross-pollination, will be difficult.

\section{Conclusions}

Understanding genetic variation of reproductive traits in common carpetgrass is important in determination of appropriate breeding strategies for improvement of the grass. The 10 genotypes showed a wide range of variation for number of spikelets per branch and seed set but had a narrow range of variation for number of branches per inflorescence. Genetic variance played a more important role than year in influence on number of branches per inflorescence, whereas the year variance component had a great impact on number of spikelets per branch. The relative importance of genotype vs. year for percentage seed set was different between the two modes of pollination. Heritability ranged from 0.07 for number of spikelets per branch to 0.50 for seed set under open pollination. Average percentage seed set of the 10 genotypes under self-pollination and open pollination was not significantly different. Among the three traits studied, percentage seed set appears to be the one that plant breeders should work with to improve seed production of common carpetgrass as a result of its wide range of variation and relatively higher heritability.

\section{Literature Cited}

Acquaah, G. 2007. Principles of plant genetics and breeding. Blackwell Pub., Malden, MA; Oxford, UK.

Acuña, C.A., A.R. Blount, K.H. Quesenberry, W.W. Hanna, and K.E. Kenworthy. 2007. Reproductive characterization of bahiagrass germplasm. Crop Sci. 47:1711-1717.

Anderson, W.F., C.C. Holbrook, and J.C. Wynne. 1991. Heritability and early-generation selection for resistance to early and late leafspot in peanut. Crop Sci. 31:588-593.

Bogdan, A.V. 1977. Tropical pasture and fodder plants. Longman, London.

Bruneau, A.H., B.R. Lassiter, G.G. Wilkerson, E.J. Erickson, C. Reynolds, J.J. Reynolds, and G.S Buol. 2008. Carpetgrass (Axonopus affinis Chase). Department of Crop Science, North Carolina State University. 13 Mar. 2014. <http://www.turffiles. ncsu.edu/PDFFiles/004259/carpetgrass.pdf>

Bush, E.W. 1997. A physiological study of common carpetgrass (Axonopus affinis) subjected to cultural and environmental stress. Ph.D. diss., Louisiana State Univ., Baton Rouge, LA.

Bush, E. 2000. Louisianagrass (Common carpetgrass): A low-maintenance lawn grass for the deep south. Louisiana Agriculture Magazine Winter:14-15.

Duble, R.L. 2013. Bermudagrass: 'The sports turf of the south.' Texas Cooperative Extension. 13 Mar. 2014. <http://aggie-horticulture.tamu.edu/ archives/parsons/turf/publications/bermuda.html>.

Duncan, R.R. 2000. Seashore paspalum: A turfgrass for tomorrow-Stress-tolerant and versatile, it promises to meet 21 st-century environmental challenges. Diversity 16:44 45 .

Greene, N., K. Kenworthy, K. Quesenberry, J. Unruh, and J. Sartain. 2008a. Variability and heritability estimates of common carpetgrass. Crop Sci. 48:2017-2025.

Greene, N., K. Kenworthy, K. Quesenberry, J. Unruh, and J. Sartain. 2008b. Diversity and relatedness of common carpetgrass germplasm. Crop Sci. 48:2298-2304.

Hallauer, A.R. 1970. Genetic variability for yield after four cycles of reciprocal recurrent selections in maize. Crop Sci. 10:482-485.

Hanna, W.W. 1995. Centipedegrass: Diversity and vulnerability. Crop Sci. 35:332-334.

Heath, M.E., R.F. Barnes, and D.S. Metcalfe. 1985. Forages: The science of grassland agriculture. Iowa State University Press, Ames, IA. p. 255 262.

Hitchcock, A.S. 1950. Manual of the grasses of the United States. USDA Misc. Publ. 200. U.S. Govt. Print Office, Washington, DC.

Hughes, H., D. Christenen, T. Koski, and S. Reid. 2002. Desert saltgrass: A potential new turfgrass. USGA Turfgrass Environ. Res. Online $1: 1-6$.

Kenna, M.P., C.M. Taliaferro, and W.L. Richardson. 1983. Comparative fertility and seed yields of parental bermudagrass clones and their singlecross F1 and F2 populations. Crop Sci. 23:11331135.

Mancino, C. F. 1988. Evaluation of curly mesquitegrass as a desert turfgrass. 1988 Turfgrass Research Summary, USGA. p. 5-6.

Piper, C.V. and L. Carrier. 1920. Carpetgrass. United States Department of Agriculture Farmers Bulletin. p. 1130.

Richardson, W.L., C.M. Taliaferro, and R.M. Abring. 1978. Fertility of eight bermudagrass clones and open-pollinated progeny from them. Crop Sci. 18:332-334.

Riordan, T. 1991. An old grass is getting a new look. USGA Green Section Record JanuaryFeb. 29:6-9.

SAS. 2012. SAS Institute, Cary, NC.

Skerman, P.J. and F. Riveros. 1990. Tropical grasses. Food and Agriculture Organization of the United Nations, Rome, Italy.

Trenholm, L. E., J. L. Cisar, and J. B. Unruh. 2011. Bahiagrass for Florida lawn. University of Florida/IFAS. ENH6.

Turgeon, A.J. 2005. Turfgrass management. 7th Ed. Prentice-Hall, Inc., Upper Saddle River, NJ.

Wang, N. 2012. Reproductive behavior of seashore paspalum (Paspalum Vaginatum Sw.). Ph.D. diss., University of Georgia, GA.

Watson, V.H. and B.L. Burson. 1985. Bahiagrass, carpetgrass, and dallisgrass, p. 255-262. In: Heath, M.E., R.F Barnes, and D.S. Metcalfe (eds.). Forages: The science of grassland agriculture. Iowa State Univ. Press, Ames, IA. 